Surgery

\section{Empyema thoracis: not time to put down the knife}

\section{Spencer}

\section{"A minor operation: one performed on somebody else" (Anon)}

$\mathrm{T}$ he incidence of empyema has increased dramatically in children over the past decade. A sevenfold increase in cases was first recorded in the UK in 1997, ${ }^{1}$ and a similar increase has recently been reported in the USA. ${ }^{2}$ Routine bacterial culture is usually negative in the UK as the great majority of patients have received antibiotics prior to referral, and this has impeded research into the cause of the phenomenon. Fortunately, new techniques have recently confirmed that the majority of our cases are due to pneumococcal infection, ${ }^{3}$ and fascinatingly that most of these cases are due to infection with organisms of serotype $1 .{ }^{4}$ This serotype is also now dominant in culture positive cases in the USA, ${ }^{2}$ and is associated with an increase of invasive pneumococcal disease in Scandinavia. In recent years serotype 14 has been the dominant cause of invasive disease in the UK, ${ }^{6}$ and until now infection with serotype 1 has been principally a problem in developing countries. The reason for this serotype shift and the mechanism of increased virulence of serotype 1 have yet to be determined. However, these findings have major implications for preventative strategies as the response to the polysaccharide vaccine is inconsistent in children under 5 years of age $^{7}$ and the new conjugate pneumococcal vaccine does not protect against this serotype. $^{8}$

This recent increase in incidence has highlighted the need to optimise management with the recognised primary short term goals of minimising time to defervescence and length of hospital stay. In addition to antibiotics, therapeutic options include aspiration, thoracocentesis with or without installation of fibrinolytics, thoracotomy with decortication, and video assisted thoracic surgery (VATS).

A major problem in the management of empyema is the formation of fibrinous adhesions resulting in loculation of the pleural fluid and entrapment of the lung. This renders it difficult to drain the pleural space and re-expand the lung by using antibiotics and thoracocentesis alone. Management in the UK has traditionally been relatively conservative, with a reliance on antibiotics and

simple thoracocentesis and a reluctance to proceed to thoracotomy because of a general perception that surgical management was dangerous and associated with significant morbidity. This approach often leads to a slow resolution of the problem with prolonged hospitalisation, as illustrated in the paper from Satish $e t$ al in this issue, ${ }^{9}$ in which the median hospital stay was 14 days. Simple aspiration is also unsatisfactory as this leads to very high rates of subsequent reintervention. ${ }^{10}$

In our experience early thoracotomy and decortication has proved to be very safe and does produce impressive results with rapid resolution of fever, discharge after a total median stay of only four days, and complete radiological and clinical resolution. ${ }^{11}$ These findings have now been confirmed in this issue by Hilliard and colleagues. ${ }^{12}$ This group also point out that patients with more severe disease who received early definitive surgery are actually discharged sooner than patients with earlier stages of disease managed with thoracocentesis, with or without additional fibrinolytic therapy.

Results from small series using VATS suggest that length of stay is longer after this procedure than with formal thoracotomy plus decortication. ${ }^{13}$ The procedure also has a small failure rate, requiring conversion to formal thoracotomy plus decortication on occasions. It is arguable whether this technique is significantly less invasive, as three intercostal incisions are usually required for insertion of instruments and drains.

\section{"Care must be taken in extrapolating adult experience into paediatric practice"}

The installation of fibrinolytics into the intercostal space via a chest drain has been successfully used to avoid formal thoracotomy in adults for some years. This approach has now been adapted to the management of this problem in children. It should be appreciated that there are important differences in the clinical picture of empyema between paediatric and adult age groups. Adult patients are often elderly and frail, and the condition is associated with significant morbidity and mortality. The vast majority of children presenting with empyema were previously well, chronic morbidity after treatment is unusual, and death extremely rare. Care must therefore be taken in extrapolating adult experience into paediatric practice. In order to clarify the benefit of fibrinolytic therapy in children, Thomson and colleagues ${ }^{14}$ conducted a multicentre randomised controlled trial (RCT) comparing the effect of installation of 40000 units of urokinase in $40 \mathrm{ml}$ with placebo (saline) into the pleural cavity twice daily for three days. This is a rare example of a multicentre RCT within the field of respiratory paediatrics not funded by the pharmaceutical industry, and contrasts with most of the uncontrolled retrospective work on this subject. Thomson et al showed that addition of urokinase did result in a reduced hospital stay compared to placebo, but this was still longer than that achieved in the uncontrolled retrospective studies of early decortication. Fibrinolytic therapy failed in $10 \%$ of patients, necessitating formal decortication. It would, of course, require a separate RCT to determine with certainty whether intention to treat by early decortication or fibrinolysis has the better outcome, but using the currently accepted outcome measures it would appear that early decortication is preferable, especially in patients with more severe disease.

Thomson et al did perform a post hoc subgroup analysis which suggested that the use of small pigtail catheters was associated with shorter hospital stay than using large bore tubes. The statistical hazards of such analyses are well known, but the possible benefit of this approach has recently been supported by findings from a further small retrospective series. ${ }^{15}$

These findings raise the question of whether we are currently using the most appropriate outcome measures. Perhaps simple measures such as length of stay and time to defervescence are too crude, and we should consider other factors when planning future studies. It is relevant to consider using other endpoints, such as the parents' and child's overall satisfaction with treatment at different timepoints. This will have several components including pain, changing attitudes to the thoracotomy scar, loss of schooling, and time off work for the carers. We also need to determine the effects of different treatments on subsequent lung growth and to monitor for the possible emergence of restrictive lung disease. There is a need to perform further RCTs to compare early decortication with fibrinolysis and VATS using such measures, but as they are much "softer" than the outcomes traditionally used; much larger numbers of patients may need to be recruited to achieve statistically significant results. 
The controversies surrounding optimal treatment have resulted in marked regional variations in management within the UK. The Royal College of Surgeons has emphasised the duties of the surgeon to keep up to date with relevant literature and to provide good clinical care. The surgeon must also utilise the knowledge and skills of other clinicians and transfer the patient to another colleague or units where the appropriate resources and skills are available if necessary. ${ }^{16}$ Both paediatricians and surgeons have a responsibility to overcome any inequities in the standards of clinical care, but geographical variations in treatment will persist until the questions regarding optimal management have been resolved.

\section{ACKNOWLEDGEMENTS}

I thank Mr Leslie Hamilton, Mr Asif Hasan, and Professor Roger Freeman for their helpful comments.

Arch Dis Child 2003;0:842-843

\section{REFERENCES}

1 Rees JHM, Spencer DA, Parikh D, et al. Increase in incidence of childhood empyema in West Midlands, UK. Lancet 1997;349:402.

2 Byington CL, Spencer LY, Johnson TA, et al. An epidemiological investigation of a sustained high rate of pediatric parapneumonic empyema: risk factors and microbiological associations. Clin Infect Dis 2002;34:434-40.

3 Eastham KM, Freeman R, Clark J, et al. A study of the epidemiology and aetiology of empyema in children. Am J Respir Crit Care Med 2002;165:A673.

4 Eltringham G, Kearns A, Freeman R, et al. Culture-negative childhood empyema is usually due to penicillin-sensitive Streptococcus pneumonia capsular serotype 1. J Clin Microbiol 2003;41:521-2.

5 Normark BH, Kalin M, Örtqvist $\AA$, et al Dynamics of penicillin-susceptible clones in invasive pneumococcal disease. J Infect Dis 2001;184:861-9.

6 Miller E, Waight $P$, Efstratiou $A$, et al Epidemiology of invasive and other pneumococcoal disease in children in England and Wales 1996-1998. Acta Paediatr 2000(suppl 435):11-16.

7 Douglas RM, Paton JC, Duncan SJ, et al. Antibody response to pneumococcal vaccination in children younger than five years of age. J Infect Dis 1983;148:131-7.
8 Shinefield H, Black S, Ray P, et al. Efficacy, immunogenicity and safety of heptavalent pneumococcal conjugate vaccine in low birth weight and preterm infants. Pediatr Infect Dis 2002;21:182-6.

9 Satish B, Bunker M, Seddon P. Management of thoracic empyema in childhood: does the pleural thickening matter? Arch Dis Child 2003;88:918-21.

10 Mitri RK, Brown SD, Zurakowski D, et al. Outcomes of primary image-guided drainage of parapneumonic effusions in children. Pediatrics 2002;110:e37,1-6.

11 Carey JA, Hamilton JRL, Spencer DA, et al. Empyema thoracis: a role for open thoracotomy and decortication. Arch Dis Child 1988;79:510-13.

12 Hilliard TN, Henderson AJ, Langton Hewer SC. Management of parapneumonic effusion and empyema. Arch Dis Child 2003;88:

13 Grewal H, Jackson RJ, Wagner CW, et al. Early video-assisted thoracic surgery in the management of empyema. Pediatrics 1999;103:e6.

14 Thomson AH, Hull J, Kumar MR, et al. Randomised trial of intrapleural urokinase in the treatment of childhood empyema. Thorax 2002:574:343-7.

15 Pierrepoint MJ, Evans A, Morris SJ, et al. Pigtail catheter treatment of empyema thoracis. Arch Dis Child 2002;87:331-2.

16 Royal College of Surgeons of England. Good surgical practice. London: RCSE, 2002. 